\title{
An anomalous origin of the middle meningeal artery
}

\author{
GAVIN ROYLE AND ROGER MOTSON
}

From the Department of Anatomy, Charing Cross Hospital Medical School, London

SUMMARY A human skull is described in which the middle meningeal artery probably arose bilaterally from the lacrimal artery. The branches of the middle meningeal vessels, however, were $\frac{\bar{c}}{\bar{\infty}}$ normal both in their position and distribution. This anomaly is a rare occurrence and is of neuro $\frac{\text { }}{\mathbb{Q}}$ surgical importance.

The skull, which had well-defined bony markings, was that of a 25 to 35 year old male with full dentition and was probably of Asiatic origin. The Cephalic Index was $81 \cdot 2$ (brachycephalic). The bones of the skull were normal and in addition there were bilateral pterion ossicles, five lambdoid sutural bones, and three parietooccipital sutural bones, two on the right and one

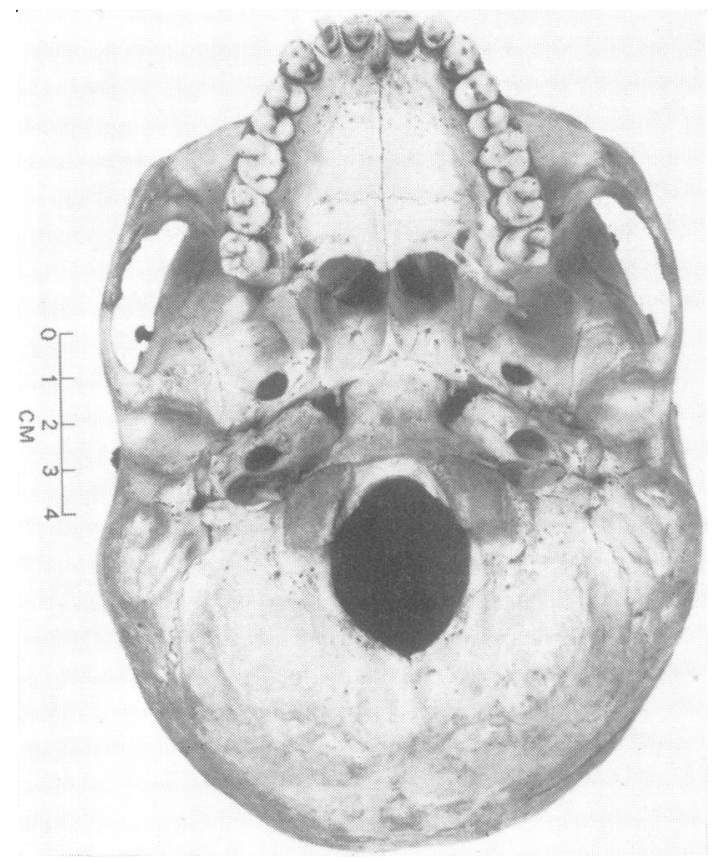

FIG. 1. Base of skull showing absence of foramen spinosum. on the left. The foramina in the base of the skult(Fig. 1) were symmetrical and within normab limits of size and distribution with the following exceptions: there was bilateral absence of the foramen spinosum, emissary sphenoidal fora men, and foramen meningo-orbitale. The forger men innominatum was present on the right sade only.

The grooves on the interior of the skull in $\mathrm{H}^{\mathrm{i}} \mathrm{z}$ cated that the main stems of the middle meningegab arteries arose from the lateral limits of the super? ior orbital fissures (Fig. 2). The origin and 迎S tribution of the vessels were bilaterally syê. metrical.

The main stem of the vessel passed laterally for $17 \mathrm{~mm}$, grooving the greater wing of the sphenoid, and ended by dividing into anterios and posterior divisions, which were normal botto in their position and distribution (Fig. 3).

In addition to the markings of the middle meningeal vessels, accessory meningeal, anteriop and posterior ethmoidal, and some small vessels supplying the anterior and posterior craniast fossae marked the skull bilaterally.

\section{DISCUSSION}

Davies and Davies (1962) state that the middle meningeal artery normally arises from the firs $\bar{\S}$ part of the maxillary artery and enters the skuls through the foramen spinosum. Its name\$ branches are anterior, posterior, superficia王. petrosal, superior tympanic, branch to the trio geminal ganglion, temporal and orbital, the latter anastomosing with the recurrent meningean branch of the lacrimal artery. The middle 


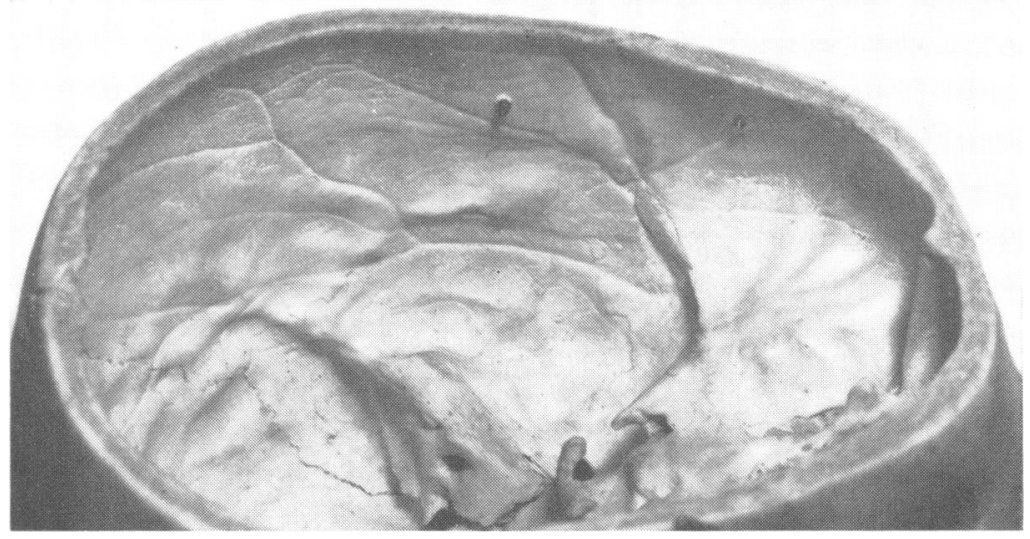

FIG. 2. View of the inside of the skull showing the left middle meningeal vessel markings.

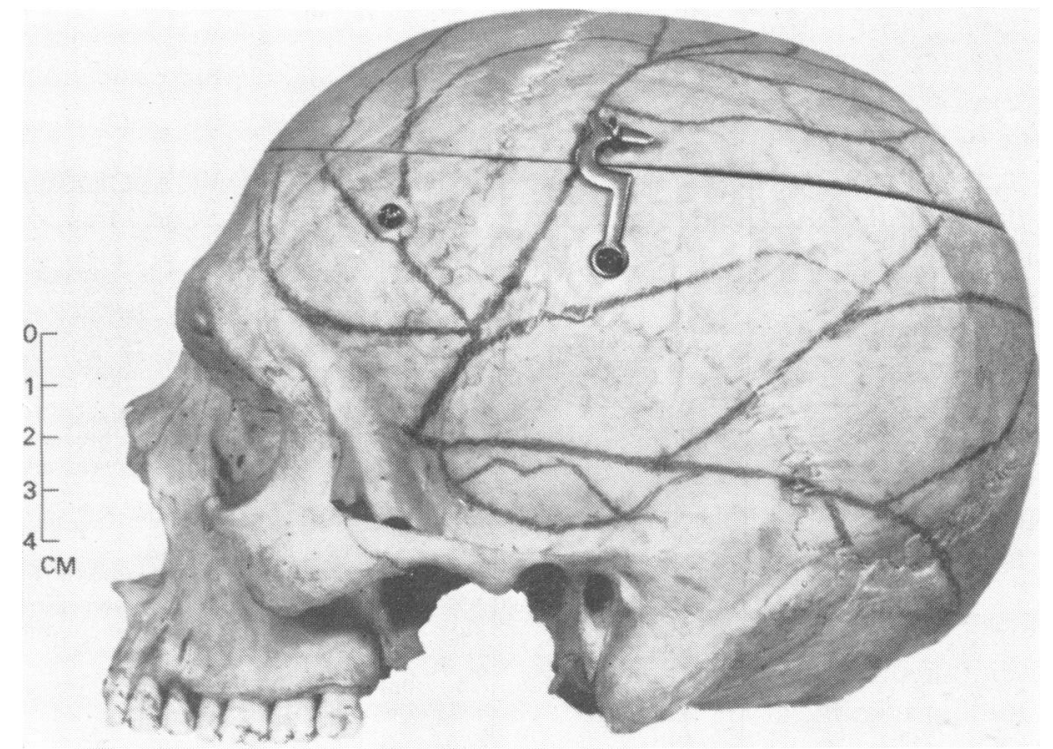

FIG. 3. View of the left side of the skull. The middle meningeal vessel markings have been traced on the outside of the skull.

meningeal veins form two principal trunks, an anterior and a posterior. The anterior either passes through the foramen spinosum to the pterygoid plexus or ends in the cavernous or sphenoparietal sinuses, forming a communication between the veins of the face and of the meninges. The posterior trunk usually passes through the foramen spinosum. The branches of the middle meningeal artery and vein accompany one another, the vein lying external to the artery. Jones (1911) states that grooves on the skull are made by the veins but indicate the position of both vein and artery. Thane (1892) states that the middle meningeal artery occasionally gives off the ophthalmic artery; rarely, the ophthalmic artery may give off the anterior division of the middle meningeal artery and, more rarely, the ophthalmic artery may give off the main stem of the middle meningeal artery itself.

Chandler and Derezinski (1935) undertook a survey of the origin and course of the middle meningeal artery in 1,200 hemi-skulls and found only a single case of the anterior division and no case of the main stem of the middle meningeal 
artery arising in the orbit. Very few cases of the main stem of the middle meningeal artery arising in the orbit have been documented. Curnow (1873) described a single case in which, on the right side only, there was a small foramen spinosum through which passed a small branch of the maxillary artery supplying only the trigeminal ganglion. A large branch of the ophthalmic artery passed through the superior orbital fissure and gave off all the other branches of the middle meningeal artery; the left side was normal. Meyer (1887) in his paper on the anatomy of the orbital arteries cited four cases originally described by Zuckerkandl (1876) in which the main stem of the middle meningeal artery arose in the orbit. Toida (1934) described one case in which the main stem of the middle meningeal artery arose in the orbits bilaterally but did not give a detailed account. Low (1946) described one case in which the main stem of the middle meningeal artery arose from the orbit bilaterally and passed through the foramen meningoorbitale just lateral to the superior orbital fissure, the foramen spinosum being absent. The groove was continued on the orbital side of the foramen passing along the lateral wall of the orbit to the inferior orbital fissure, indicating that the origin of the middle meningeal artery was from the third part of the maxillary artery. In our case the foramen meningo-orbitale was absent bilaterally and there were no vascular markings in the orbit continuous with those of the middle meningeal artery in the skull.

The origin of this anomalous middle meningeal artery can be explained on a developmental basis. Padget (1948) found that the middle meningeal artery is formed from the common stem of the maxillary and mandibular branches of the stapedial artery (the maxillary branch of the external carotid artery fuses with this stem) and from the proximal part of the supraorbital branch of the stapedial artery. The lacrimal artery is formed from the distal part of the supraorbital branch of the stapedial artery and from a branch of the ophthalmic artery which anastomoses with it. Thus the supraorbital branch of the stapedial artery is common to both the middle meningeal and lacrimal arteries, explain ing the normal anastomosis between them. In the adult the recurrent branch of the lacrimal arteryo either passes through the foramen meningo 0 orbitale when present or through the superioro orbital fissure.

Thus, in the case described in this paper, the middle meningeal artery probably arose bi laterally from the lacrimal artery. The middle $e^{\frac{P}{+}}$ meningeal veins probably drained into the superior ophthalmic veins.

The origin and distribution of the middle meningeal vessels is of surgical importance-for example, concerning extradural haemorrhage. Knowledge of their anomalies is therefore also of importance.

This paper describes a rare anomaly of which very few cases have been documented and none previously photographed.

We would like to thank Professor T. W. A. Glenister and Dr. J. R. W. Ross for their advice and Mr. R.S. Barnett for taking the photographs.

\section{REFERENCES}

Chandler, S. B., and Derezinski, C. F. (1935). The variations of the middle meningeal artery within the middle craipaf fossa. Anatomical Record, 62, 309-319.

Curnow, J. (1873). Two instances of irregular ophthalmic middle meningeal arteries. Journal of Anatomy ande Physiology, 8, 155-156.

Davies, D. V., and Davies, F. (Eds.) (1962). Gray's Anatomy 33rd edn, pp. 777 and 883. Longmans: London.

Jones, F. Wood (1912). On the grooves and origins upon the ossa parietalia commonly said to be caused by the arteria meningea media. Journal of Anatomy and Physiology, 460 228-236.

Low, F. N. (1946). An anomalous middle meningeal arteryฉ Anatomical Record, 95, 347-351.

Meyer, F. (1887). Zur Anatomie der Orbitalarterien. Mor윽 phologisches Jahrbuch, Leipzig, 12, 414-458.

Padget, D. H. (1948). The development of the cranial arteries in the human embryo. Contributions to Embryology? Carnegie Institute of Washington, 32, 205-261.

Thane, G. D. (1892). Arthrology-myology-angeiology? In Quain's Elements of Anatomy. Vol. 2, pt 2, 10th edn, p? 407. Longman: London.

Toida, N. (1934). Ueber die endokranischen Furchen dee arteria meningea media bei den Chinesen. Journal of Oriental Medicine, 21, 13-14.

Zuckerkandl, E. (1876). Zur Anatomie der Orbitalarterien? Medizinische Jahrbiicher der K.K. Gesellschaft der Arzte zu Wien, 343-350. 